\title{
ACQUISITION OF FRENCH ADJECTIVES IN QUEBEC FRENCH AS REVEALED BY
}

\section{ELICITATION DATA}

\author{
Phaedra Royle $e^{1,2,3}$ and Daniel Valois ${ }^{1,4}$ \\ ${ }^{1}$ Université de Montréal \\ ${ }^{2}$ Centre hospitalier universitaire Ste-Justine \\ ${ }^{3}$ Centre for research on Language Mind and Brain \\ ${ }^{4}$ Institut des Sciences Cognitives
}

\begin{abstract}
This study presents data from an elicitation study on French size and color adjectives in noun phrases (DPs), both early acquired structures. Thirty-two francophone children aged 3-5 years participated in the study. Adjectives were elicited using specially designed puzzles and spontaneous speech corpora. We observed that errors in French variable adjectives are produced in the early acquisition stages, especially in the context of feminine colour DPs. We propose that the source of difficulty for feminine variable adjectives is the retrieval of a lexicalized form that competes with the masculine adjective denoting the same concept.
\end{abstract}

\section{[95 words]}

Key words : Concord, French, Adjectives, Elicitation 
This study aims to shed light on the acquisition of concord in French and provide insight into linguistic theoretic and psycholinguistic models of language acquisition. Spontaneous and elicited speech data were gathered from a cross-sectional study of French-speaking children aged $3-5$ years. The structure of interest is adjectives in the complex noun phrase (also called the Determiner Phrase or DP). In French, a number of adjectives are variable, having feminine and masculine forms that agree with the masculine or feminine noun of the DP (e.g., la maison verte 'the green house,' le bateau vert 'the green boat'). By examining this structure acquired at early word combination stages, we investigate agreement relations in very young speakers and verify whether this structure can inform us on the nature of lexical rules and access to the lexicon.

\section{Gender}

Gender is a linguistic feature by which words in a given language are assigned to a class. This has consequences for the forms taken by other elements related to the word (Comrie, 1999) (e.g., nouns and their determiners or adjectives). French has two genders: masculine and feminine. Nouns are most often classified into either gender on a relatively arbitrary basis. For example chaise 'chair' is feminine, whereas banc 'stool' is masculine. As in most languages with gender, French shows some correlations with natural gender (i.e., inherent, as opposed to grammatical, gender). Not unexpectedly, femme 'woman' is feminine and homme 'man' is masculine. There are also correlations between formal properties of French nouns, usually final segments (consonants or syllables) and their gender, and these vary according to the segment (Desrochers et al., 1989). For example, a noun ending in [p], such as moppe 'mop,' has little predictive value as to its gender in French, while words ending in [on], such as couronne 'crown,' have a strong chance of being feminine. In addition, most derivational suffixes have inherent gender. For example, the suffix - euse meaning 'doer of V' (laveuse 'washer(-woman),' 
sècheuse 'dryer,' repasseuse '(flat)-iron,') derives a feminine noun and ends in the consonant $-z$. It is important to note that correlation research rarely distinguishes between word final consonant metrics and the presence of a derivational suffix.

Gender is realized on determiners (le/la 'the.m/f'; un/une 'a.m/f'; tout/e 'all'), third person singular and plural pronoun clitics (il/elle 'he/she'; ils/elles 'they.m/f.'), possessive, demonstrative, indefinite and relative pronouns (e.g., le mien/la mienne 'mine.m/.f'; celuilà/celle-là 'that one.m/f'; aucun/e 'no(ne).m/f'; lequel/laquelle 'which.m/f', etc.), a subset of adjectives (see below) and past participle forms of verbs (elle s'est assise/il s'est assis 'she/he CL.AUX sat.m/f'). ${ }^{1}$ Gender is therefore a salient grammatical property of French, and, as such, a feature that must be acquired in order to master the language.

Theories of lexical acquisition

A number of language acquisition models have been proposed to account for the acquisition and processing of morphosyntactic and lexical structures. These models can generally be classified as rule- versus item-based. Rule-based models originate in linguistic theories of grammar and are believed to instantiate innate, modular, automatic, fast and obligatory processes. Examples of this type of model are proposed in Aronoff (1976), for lexemes, but more recent examples can be found. For instance, Stockall and Marantz (2006) proposed a model for the processing of inflected English verbs based on brain imaging experiments. Item-based models, on the other hand, ascribe relatively more importance to input in the development of linguistic representations. For example, Bybee and Slobin (1982) and Marchman and Bates (1991, 1994) propose that the acquisition of inflectional paradigms, such as the English past tense, is linked to

\footnotetext{
${ }^{1}$ However this last type is less robust in colloquial Quebec French than in standard dialects (Pirvulescu and Belzil, 2008).
} 
the high token frequency or high regularity of these patterns in the input. Finally, a number of hybrid models incorporating aspects of item- and rule-based approaches have been proposed, particularly in the domain of lexical learning and processing. These models generally maintain that both rule-based and item-based learning can occur at the same time. For example, Burani and Caramazza (1987) propose that known derived words are accessed whole by adult Italian speakers, while lower-frequency and newly learned words are decomposed into their morphemes during processing. Acquisition models generally hold that regular (sometimes, default) and semantically transparent structures can be morphologically analyzed, but not when the structure is irregular (Clahsen and Rothweiler, 1992; Marcus et al, 1992, 1995; Kim, et al. 1994; Pinker and Prince, 1994; Royle, 2007) or semantically opaque (Bertram et al., 2000a; 2000b).

In this context, the study of French can address a number of aspects of language acquisition that are relevant to theories of lexical representation and language acquisition. In particular, French is a morphologically richer language than English in some respects, while presenting idiosyncrasies that make structures difficult to acquire. Royle (2007) showed that French-speaking children from Québec are sensitive to the morphological structure of verbs, distinguishing between regular and irregular verbs. French-speaking children produce more target past tense forms under prompting when presented with regular versus irregular verbs. This occurs on early-acquired as well as low-frequency verbs. Children also tend to overregularize irregular verbs, especially if they are low-frequency. In addition, some regularization occurs into the second conjugation (-ir), which has lower type and token frequency than the default -er conjugation in French. Royle concludes that French-speaking children are sensitive to verb conjugation groups at early ages and that paradigm frequency in the corpus does not affect French-speaking children's ability to recognize these patterns. St-Pierre (2006) studied the processing of irregular verbs and adjectives with latent consonants in school-aged French- 
speaking children. St-Pierre (2006) found that the production of these forms is highly mediated by their frequencies: final consonants are more correctly produced on high-frequency than lowfrequency forms. This finding suggests that the acquisition of these forms should be described as item-based rather than rule-based, and that a "pattern" for the production of consonant final alternations emerges from the input (this is postulated within a connectionist framework that disallows rules in the sense of Marcus's “operations over variables," 2001). The data from French provided by Royle and St-Pierre seem to indicate that irregular verbs and adjectives are processed using mnesic abilities, whereas regular verbs (e.g., -er and -ir verbs) are processed using rules. We still do not know how children learn the masculine-feminine opposition governing French variable adjectives. Before we present data from French child corpora, we describe intra-nominal agreement and review proposals accounting for variable adjectives in French.

\section{French DP and Intra-Nominal Agreement}

The French DP has a number of interesting features, making it useful for the study of adjective acquisition. One is the presence of agreement operations (or concord) between nouns and adjectives (1).

$\begin{array}{ll}\text { 1) La voiture brune } & \text { Le camion brun } \\ \text { the.f car brown.f } & \text { the.m truck brown.m } \\ \text { [la vwatyь bьyn] } & \text { [lœ kamjõ brœ̃ }] \\ \text { 'the brown car' } & \text { 'the brown truck' }\end{array}$

Variable French adjectives have word-final consonants that appear on the feminine forms only (see examples in Table 1). These consonants are somewhat arbitrary and cannot generally be 
adduced based on the masculine forms, except for some forms ending in $-n$ in the feminine, which have nasalized vowels in the masculine. However, not all masculine forms ending in nasalized vowels have n-final feminine forms, e.g., blanc [blã] - blanche [blãf] 'white.m/f'. These variable adjectives, and other French words involving word-final consonant alternations, have been described as having "floating" or "latent" consonants that are realized under specific conditions (see Paradis and El Fenne, 1995, for a review of different approaches).

\section{INSERT TABLE 1 HERE}

Within the framework of constraints and repairs, Paradis and El Fenne (1995) propose that the best way to account for different word forms in French is to posit a consonant deletion process in the absence of a timing slot (for example, syllabification can occur before an empty onset, or in a feminine form). However, this analysis is disputed in Picard (1996) due to its post lexical nature. An illustration of this is presented in $2 \mathrm{~b}$, where the masculine petit /pœeti/ becomes [pœtsit] before an onsetless syllable in the following word (termed liaison).

2)
a. Petit
small.m
[pœt $\left.{ }^{\mathrm{s}} \mathrm{i}\right]$
b. Petit insecte
small.m insect
[pœtsitinsek(t)]
c. Petite
small.f
[pœtsit]
d. Petite fourmi
small.f ant
[pœt $\left.{ }^{\mathrm{sit}}(\mathrm{e}) f u r m i\right]$

More recent optimality-theoretic approaches have accounted for consonant/Ø alternations in languages such as French. Tranel (2000) suggested an explanation of this type for liaison; 
however, he leaves open the question of whether these consonants are "borrowed" from the feminine form or whether they are of a completely different nature (some adjectives, for example grand 'big.m', have a different consonant for the feminine grande [gкãd] and for masculine liaison grand [gธãt]). ${ }^{2}$

The fact remains that a morphological description of the transition from masculine (the default $^{3}$ in French, Fink, 1985; Nelson, 2005) to feminine form is difficult and somewhat arbitrary. We could posit that there is actually no productive morphological rule for adjective gender marking in French, and there is some evidence to supports this. First, in terms of linguistic productivity, no overregularizations into this pattern have been observed (ex. étanche $\rightarrow$ *étanc 'water-/air-tight', by analogy with blanche $\rightarrow$ blanc 'white'). Furthermore neologisms and borrowings are systematically integrated into the invariable pattern (e.g., hot, laïc 'secular') and not into the consonant/ $\varnothing$ pattern (Herschensohen, 1993). Finally, experiments on neologism processing show that French speakers do not insert or delete final consonants, but instead tend to preserve the presented forms (e.g., bravais/e) (89\% of responses) (Fink, 1986). The first two facts are linguistic indicators of a default rule (Wurzel, 1984, Marcus et al., 1995, Dressler, 1997), and Fink's experimental data support that this default rule implies no change. Based on this interpretation, we could argue that feminine forms are not constructed via morphologically-based inflectional processes, but instead are stored as such in the lexicon, in the same way as irregular and suppletive verb forms.

\footnotetext{
${ }^{2}$ Tranel (2000) argues against a general rule of consonant deletion in French because he observes a process of consonant insertion for cardinal numerals (e.g., six cours 'six classes' can be alternately pronounced in the standard [sikur] or nonstandard form [siskur]), thus the contrary pattern from that described by consonant deletion rules. He concludes that variable adjectives should be subject to a similar morphophonological rule of consonant insertion.

${ }^{3}$ Default forms are used in neutral conditions (e.g., c'est chaud 'it's hot') and when there is competition between feminine and masculine agreement (e.g., le bateau et la voiture verts 'the green.m.pl boat m. and car f.').
} 


\section{Corpora studies}

An analysis of the CHILDES corpus from a French-speaking child from Montreal (De Cat and Plunkett, 2002) reveals the use of adjectives in complex DPs with feminine forms (e.g., petite 'small.f') starting around age 2 years and 3 months. A study of noun-drop production in DPs in spontaneous speech samples of French-speaking children aged 2 to 3 years $(N=14)$ reveals that French-speaking children produce feminine forms of variable attributive adjectives as young as 26 months (2 years and two months) (Valois et al., to appear). Of the 103 instances of attributive adjectives produced in the corpus, 62 are variable. Of these, 41 are in feminine DPs, and only one is erroneously produced in its masculine form. This is not to say that French-speaking children completely master the French gender agreement system at these ages. ${ }^{4}$ A verification of the Valois et al. corpus reveals a number of difficulties. Errors can be seen in the production of predicative adjectives (e.g., in the constructions elle est jaune, belle et *brun 'it.f is yellow, beautiful.f and brown.m.', 2:2), and singular determiners ${ }^{5}$ (e.g., *une café 'a/one.f coffee', 2:1, or *le maman 'the.m mother', 2:0). Errors on attributive adjectives also occur (in 5 of 11 feminine variable forms, or $45.5 \%$, and 2 of 26 masculine variable forms, or $7.7 \%$ ). However, these structures are not very common in the language samples, as only 69 attributive adjectives were produced overall (48 masculine and 21 feminine, including invariable forms). Some children do not produce these structures at all, and of those who do, not all produce forms demanding the feminine (a total of 1,904 utterances are analyzed in the corpus). A subsequent study of N-Drop taken from the longitudinal Pauline corpus (Bassano and Maillochon, 1994) in CHILDES (MacWhinney and Snow, 1990) reveals similar behaviour. Valois and Royle (2009) show that,

\footnotetext{
${ }^{4}$ We do not discuss verb agreement here.

${ }^{5}$ Plural determiners are not marked for gender.
} 
although Pauline produces feminine variable adjectives, she does not produce many types, and she makes mistakes on these same types. Table 2 presents an overview of different variable adjectives produced by the children in the two studies.

\section{INSERT TABLE 2 HERE}

As can be seen, petit/e, gros/se, grand/e and vert/e are the most commonly produced forms. However, except for petit, no form is produced by more than half of the children in the Sutton corpus. Therefore, there is not much variety in terms of variable adjectives within the corpus, and even less so for each given child (excluding Pauline's longitudinal corpus, only one child, aged 2;11, produced four different variable adjectives in the feminine). Moreover, Pauline makes errors on the earliest acquired forms (petite and blanche), which she subsequently produces correctly in the same recordings. Thus, the data in the spontaneous speech corpus do clearly indicate productive agreement abilities, and the age of mastery, and whether adjective concord is truly mastered, remain in dispute. It is arguable that the children are producing lexicalized chunks à la Tomasello (2002), or collocations, without checking agreement.

In order to address this issue, we designed an experiment to elicit size and colour adjectives. To date, no elicitation study of the acquisition course of this structure in pre-schoolaged French has been undertaken. The study of DPs in French allowed us to add cross-linguistic data to the research on acquisition of concord. More importantly, we could verify whether the acquisition of concord is sensitive to features such as morphological regularity, as French is manifestly not regular in this respect. We expected this lack of regularity to negatively affect French-children's ability to produce appropriate forms of variable adjectives in elicitation experiments. 
Elicitation studies

DPs are relatively easy to elicit (e.g., as opposed to VPs or clauses) in very young children. A pilot project to elicit variable adjectives revealed that very young children (aged 2;0 $4 ; 2, N=16$ ) can perform adjective production tasks for DPs in French, reliably naming colours at around age 2;4, and producing size and colour adjectives around the age of 2;6 (Royle et al., 2005). However, these children had not completely mastered all adjectives, especially feminine forms. In addition, because only variable adjectives were elicited by Royle et al., information on the effect of variability versus the presence of a word-final consonant on target production is lacking. Bedore and Leonard (2001) studied grammatical morphology in Spanish-speaking children (two groups aged 2;4-3;10, 4-5;6, $N=30$ ). They elicited the production of target structures using picture description tasks (singular and plural items). Results show that Spanishspeaking children score between $88 \%$ and $94 \%$ correct on adjective agreement. The highest number of errors occurred on feminine plural forms, which tended to be replaced by masculine plural or feminine singular forms, e.g., rojas 'red.f.pl' $\rightarrow$ rojos 'red.m.pl' and roja 'red.f.sg'. Errors on masculine adjectives were rare. A similar study was run on Swedish-speaking children (two groups, aged 2;1-3;7 and 4;3-5;7, $N=28$ ) (Leonard et al., 2001). Children were asked to finish contrasting sentences of the type 'This is a green house and this is ... Target: a yellow car., Few gender errors were observed, with 14 gender errors on adjectives in the younger group and 11 in the older group. The most common errors involved definiteness (e.g., production of det stort tåget for det stora tåget 'the big.indef train' for 'the big.def train'), which must be marked on the determiner and adjective. However, the data is difficult to interpret, as total numbers of target and correct (non-target) production of adjectives are not presented. 
More recently, Roulet-Amiot and Jakubowicz (2006) investigated the elicited production and processing of French gender, focussing on determiners and adjectives in the DP. This study included two groups, aged 4;4 - 4;11 and 6;4 - 6;11. They evaluated children's ability to produce appropriate determiners and pre- or postnominal attributive adjectives in a picture description task and verified interference effects of disagreement (e.g., un *nouvelle balai 'a.m new.f broom') in a semantic categorization task. Significantly more errors were observed on the overall production of feminine DPs, and masculine forms were produced as a default. ${ }^{6}$ However, the older group did not show a masculine/feminine asymmetry in their errors and made few errors overall ( $5.2 \%$ on average). During the perception task, the experimenter gave the child some background context (e.g., "Now the monkey is going to the store where one can buy clothes, things we can wear. Do you think that in this store, it will be able to buy...'), and the child was then presented with one of three response types: grammatical, ungrammatical determiner (e.g., *une nouveau balai), and ungrammatical adjective (e.g., un *nouvelle balai). The child was asked to respond YES or NO by pushing a button. Reaction times (RTs) and error rates were recorded. Only the older group was able to perform semantic categorization. They showed an agreement effect, where children produce faster RTs on concordant stimuli than non-concordant ones. However, this effect was found only for the discordant determiner condition and did not reach significance for the adjective condition, although a trend was found. Error rates in the 6year-olds were similar to those found in adults ( $5.8 \%$ vs. $4.1 \%)$. These data show that mastery of DP agreement emerges sometime between 4 and 6 years old in French-speaking children, and that definite determiners are reliably produced with appropriate gender at 4 years in French. However, the data on adjectives does not show such robust effects.

\footnotetext{
${ }^{6}$ The authors link production errors to the absence of N-movement within the DP, based on the fact that a number of the children's responses do not follow canonical word order. However, no furthers details are given with respect to word order. (See footnote 2 on this.)
} 
The above-presented experiments were run to investigate the nature of specific language impairment in Spanish, Swedish and French. The focus of the analyses was therefore on impaired language, with control children serving as benchmarks for normal language acquisition. Little information is given about their production abilities, overregularization patterns (if any), alternate production strategies, and so forth. In addition, the picture description and contrastive approaches used to elicit complex DPs in these children raise the possibility that the child focussed on some aspect of the drawing that was not relevant to the study, and thus produced non-target adjectives. ${ }^{7}$ We therefore decided to design a controlled elicitation task comparing the use of variable and invariable adjectives in order to document typical language acquisition patterns and verify whether the ability to produce variable adjectives is acquired early in French.

Research questions

The present study aims to bring together data from spontaneous speech samples and elicited tasks in order to verify whether children show productive rule-governed behaviour when producing DP-internal adjective concord at young ages. It also aims to determine when DP concord becomes productive, and whether this morphosyntactic process is correlated with productivity in the spontaneous corpus and other morphosyntactic processes involving gender agreement, such as determiner concord.

We posit a number of hypotheses relating to the acquisition of concord, but also to theories of language acquisition. A first general hypothesis draws on previous research on agreement in language. Following Valois and collaborators' studies (2009, in press), we propose

\footnotetext{
${ }^{7}$ An example from our own pilot study is a child's focus on the smoke coming out of a boat's chimney. She produced structures such as je veux le gros bateau brun avec la fumée 'I want the big brown boat with smoke' for the target je veux le gros bateau brun 'I want the big brown boat.' Smoke was eliminated from the picture.
} 
that concord (i.e., checking for agreement within the DP) is acquired early in French, but that different structures in the DP are productively produced at different acquisition stages. More specifically, determiners are the first to emerge, and are mastered quite rapidly with low error levels, whereas variable adjectives take longer to master due to the idiosyncratic nature of feminine variable forms. ${ }^{8}$ Accordingly, the rule linking feminine and masculine adjectival forms (if rule there is) should emerge only in later acquisition stages.

If the correct production of feminine adjectives is related to the acquisition of specific and idiosyncratic lexemes, then we should expect mastery of the elicited feminine structures to be strongly related to lexical acquisition of the feminine forms. That is, even if the child knows the masculine form of the adjective, we should observe some difficulty in production when the feminine counterpart is required. In theory, we would also expect occasional reversals of this pattern, i.e. comprehension or production of the feminine but not the masculine form, for children having learned only the feminine. However, because the masculine is the default in French, we would not expect to observe this pattern often, especially because we expect the children will be old enough to have acquired the semantics of the experimental lexical items.

Finally, if spontaneous speech corpora reflect the emergence and acquisition of linguistic rules, we expect to observe parallels between children's agreement productions in the spontaneous speech samples and their ability to produce the elicited structures. We expect types and tokens to be relatively common and without error in the corpora of children having no difficulty doing the tasks. Nonetheless, we might observe a relative lack of these structures in the corpora, even in children able to perform the tasks, because adjectives are not obligatory (unlike determiners), but also due to the deictic nature of play situations in which the spontaneous speech is gathered (i.e., children can point to rather than describe the topic).

\footnotetext{
${ }^{8}$ However, see Paradis and El Fenne (1995).
} 
Methodology

Participants

Thirty-two French-speaking children (15 boys, 17 girls) from the greater Montreal area were recruited for our study. These children were controls participating in a larger project assessing agreement processes in children with a language disorder (Royle, 2005 to 2008). Four children from each 3-month age range between 3 and 5 years old ( 8 subgroups) participated in the experiment. Table 3 presents an overview of children's characteristics. All children were from unilingual French families and were exposed almost exclusively ( $>80 \%$ exposure) to French during childhood. ${ }^{9}$ Parents were asked to fill out a questionnaire on the child's developmental history to ensure that cognitive and linguistic development was normal. All children were screened for hearing abilities at the beginning of the first encounter. A hearing threshold (in both ears) above 20 at $500 \mathrm{~Hz}$, or 15 at 1000, 2000, and $4000 \mathrm{~Hz}$, resulted in the child being excluded from the experiment.

\section{INSERT TABLE 3 HERE}

\section{Materials}

In order to encourage the children to produce the structures of interest, we developed puzzles containing pieces with images varying in color or size. The participants had to indicate the size or colour of the piece they wanted in order to fill out the puzzle. These were similar to children's puzzles mass-produced in North-America and Europe. Their resemblance to children's

\footnotetext{
${ }^{9}$ It is hard to find children in the greater Montreal who have never been exposed to another language. However, many French children do grow up in monolingual settings and are significantly exposed to another language only after they enter primary school.
} 
everyday toys made them ecologically valid tools. Similar methods have been used to elicit agreement in Spanish and French DPs (Royle et al., 2005) and case-marking in German- and Japanese-speaking children (Matsuo and Eisenbeiss, 2003).

Four puzzles varied in terms of syntactic complexity and type of adjective elicited (colour or size). The first verified colour adjective vocabulary. The second depicted nouns that varied in size (e.g., the big horse, the small horse). The third depicted nouns that varied in colour (e.g., the pink horse, the blue horse). A fourth puzzle verified structures containing nouns that varied in both colour and size (e.g., the big blue horse, the small pink horse). The puzzles were designed to force the child to name the attribute (size or colour) of the noun in order to get the desired piece. The images were printed on the background of the puzzle board and on the pieces. Level of visual complexity was controlled for. The drawings were created by a professional artist and the boards and pieces by a woodworker.

\section{Stimuli}

All adjectives and nouns used were early acquired and high frequency in French. Data from an ongoing project on lexical development in French-speaking children were verified to ensure age-appropriate stimuli for three-year old children (Trudeau et al., 2008). In addition, frequency was verified using two web-based corpora for French $\left(\operatorname{LEXICUM}^{10}\right.$ and LEXIQUE, New et al., 2004). The variable adjectives had been piloted on 16 French-speaking children from Montreal, aged 2-4 years (see Royle et al., 2005) with additional invariable adjectives for the present experiment. Choice of invariable stimuli was based on frequency and phonological similarity, in terms of word-final consonant, to feminine forms (see Appendix A). These were difficult choices to make due to age of acquisition constraints. Therefore, only two of three pairs

${ }^{10} \mathrm{http} / / /$ retour.iro.umontreal.ca/cgi-bin/lexiqum 
were matched on all features. Because of the number of adjectives used in colour DP tasks (3 variable, 3 invariable, in both masculine and feminine forms), we divided the colour items into two lists (A and B versions, each containing feminine and masculine forms of half of the six adjectives). The child was presented with all the different adjectives, but not in all possible (masculine and feminine) combinations.

Procedure

Participants and their parents were asked to come to the research lab for two sessions lasting approximately one and a half hours (Centre de réadaptation Marie-Enfant, CHU SainteJustine, Montreal, Canada). They accomplished all tasks with a research assistant or the first author in a sound-proof recording lab equipped with an observation post (two-way mirror). The children participated in a number of linguistic and cognitive tasks with and without established norms to evaluate their development and obtain a more complete linguistic profile. The tasks also allowed us to verify that the children were acquiring language normally. They included a French version of the Peabody receptive vocabulary task (Dunn et al., 1993), a working-memory evaluation using the Memory Screen subtest of the Leiter (Roid and Miller, 1996), a hearing screen, and a spontaneous speech sampling session to verify the use of morphosyntactic structures of interest and determine mean length of utterance (MLU), a quasi-syntactic measure of language development. In addition, because elicitation tasks can be extremely specific in their domain of inquiry (here, DP structures involving one or two size or colour adjectives and concrete objects or animals) the spontaneous speech samples were used to link elicited verbal behaviour to a more naturalistic sample. Audio-video recordings were made of the spontaneous speech sessions. Non-directive speech was used in these sessions, during which the children played with a set of toys (house, circus train, play dough, bus). Parents were asked not to interact 
orally with the children during the experiment. They could observe the children through the twoway mirror or sit with the child if he/she was too shy to stay alone with the experimenter. Spontaneous speech samples were coded using the SALT program (Systemic Analysis of Language Transcripts, Miller and Chapman, 1984-2002) adapted for French (Elin Thordardottir, 2005). MLU counts in morphemes and words were based on a sample of 200 utterances.

During the puzzle tasks, the experimenter installed a screen between herself and the child to avoid deictic pointing in place of oral production. Experimental sessions consisted of a serial presentation of the puzzles in ascending order of difficulty. Two practice stimuli were initially presented to the child, with models of target answers provided orally. The child was then encouraged to ask for the piece they wanted. If the child successfully performed the first task, the experiment moved on to the second puzzle, and so on. Following the production task, a comprehension task was run using the same materials. The roles of the experimenter and the child were reversed and the same procedure was applied. All responses were recorded and entered into a database. Percentage target responses and deviant productions were noted.

Results

\section{Colour words}

Numbers of target responses were entered into an analysis of variance (ANOVA) with adjective type (variable, invariable) as the independent within-subject variable. A main effect of adjective type was found, showing that variable adjectives were more difficult to name (mean $74 \%$ ) than invariable ones (mean 93\%) overall $(F(1,31) 26.43, p<0.001)$. However this effect seemed to be specifically related to the item brun 'brown,' which resulted in lower naming accuracy (mean 40.6\%). Blanc 'white' also showed slightly lower naming accuracy at $84.4 \%$. All 
other colours were named at a rate of over $90 \%$ on average. Difficulties with brun could be related to the lower frequency of this item (see Appendix A).

In order to verify whether results varied with age, we entered age (eight groups) as a between-subject factor into our ANOVA. Age was not a significant factor affecting results $(F(7$, 24) $0.27, n s$ ), indicating that the ability to name colours was generally acquired in these children, independently of age group. Sex was also entered as a between-subject factor (17 girls, 15 boys), and no significant main effects on response accuracy were found $(F(1,30) 1.26, n s)$.

Non-target responses included no response ( 20 items, 8 for brun 'brown', and 5 for blanc 'white,' with the remainder for various items) and production of other colours (11/12 for brun), such as gris 'grey,' chocolat or violet. When this type of error was produced, experimenters presented the child with a correct model of the target colour for subsequent tasks.

When tested on comprehension of colour terms, the average result was $94 \%(S D=13)$. Only two children (aged 3;4 and 4;2) showed 50\% errors on comprehension of these items. Target levels were balanced across all items (30/32 or $93.5 \%$ to $31 / 32$, or $96.88 \%$ correct on all items)

Size adjective DPS

Numbers of correct adjectives produced were entered into a $2 \times 2 \times 2$ analysis of variance with gender (masculine and feminine), size (big and small) and animacy (animate vs. inanimate nouns $)^{11}$ as independent variables. A main effect of gender was found $(F(1,31) 5.17, p<.05)$ : masculine size adjectives were produced more accurately (94\%) than feminine ones (81\%). Other factors showed no significant main effects (all $p \mathrm{~s}>0.1$ ).

\footnotetext{
${ }^{11}$ We noticed that some children produced maman or papa for grand(e) 'big,' and bébé 'baby' for petite 'small.' We therefore added animacy to the computations.
} 
Age was entered as a between subject factor (eight groups) and was not found to be a significant factor mediating target production, but barely $(F(7,24) 2.24, p=0.07)$, showing that some younger groups might have difficulties not observed in older cohorts on these adjectives. However, we note that accuracy is quite high in all children, with a mean response accuracy of $90.6 \%(\mathrm{SD}=9.3)$ across age groups. No effect of sex was found on response patterns $(F(1,30)$ $1.26, \mathrm{~ns})$.

Gender errors (e.g., la gros maison 'the.f big.m house') accounted for 7\% of responses, all on feminine DPs, while 3.5\% of responses involved adjective commission (i.e., providing the wrong adjective, e.g., papa bateau 'daddy boat' for 'the big boat'). Adjective omission and refusal to respond were rare. The mean score for size DP comprehension was $98 \%(S D=4)$. No child scored below 7/8 (or $87.5 \%$ ). Target responses were balanced across all items (at $31 / 32$ or 32/32), with no difference between masculine and feminine items (both 98.4\%).

\section{Colour adjective DPS}

We combined results for the 32 children, as each child produced only half of all the stimuli in this task (task version A or B). We entered the data on target adjective production into a $2 \times 2 \times 3$ analysis of variance with gender (masculine and feminine), adjective type (variable and invariable) and items ( 3 adjectives) as independent variables. Main effects of gender $(F(1,15)$ $39.05, p<.001)$ and adjective type $(F(1,15) 46.99 ., p<.001)$ were found, as well as an interaction between the two factors $(F(1,15) 52.57, p<.001)$. Means for target responses are presented in Table 4.

\section{INSERT TABLE 4 HERE}


As in the previous task, masculine forms were better produced than feminine ones overall. As in the first task, invariable adjectives were better produced than variable ones overall. Finally, the interaction of these factors reveals that variable feminine forms were the most difficult to produce and resulted in the lowest rates of target production.

We entered age (eight groups) as a between-subject factor in our analysis. Age had a significant main impact on results $(F(7,8) 3.97, p<.05)$ and showed an interaction with items $(F(1,7) 5.69, p<.02)$, indicating that some items (e.g., brune) were still being acquired. Sex did not show inter-subject effects on response patterns $(F(1,14) 0.57$, ns). Figure 1 presents mean response accuracy on the four tasks by age group ( 4 children in each group). Again, the younger group seems to be in the process of acquiring and consolidating knowledge of colour adjectives, although less well than what was seen for size adjectives.

\section{INSERT FIGURE 1 HERE}

Common non-target responses included gender errors on the adjective $(12.4 \%$ of responses, all on feminine targets). Adjective omission (e.g., le canard for le canard rouge 'the red duck') and no response accounted for five percent of the data, while adjective commission (e.g., le gros canard 'the big duck' or le canard gris 'the grey duck' for le canard brun 'the brown duck') was observed in $3.6 \%$ of cases.

We verified whether the coda consonant structure might affect production by comparing results on feminine targets for jaune vs. brune [zon - bryn] containing a final nasal with rouge vs. blanche [виз - blãf] containing a final fricative. Student T-tests revealed significant differences between jaune $(M=100 \%)$ and brune $(M=13 \%)(t(15) 10.24, p<.01)$ and between 
rouge $(M=100 \%)$ and blanche $(M=56 \%)(t(15) 3.42, p<.01)$. This suggests that difficulties in production of variable feminine forms do not seem to be related solely to the presence of a wordfinal consonant.

Comprehension of colour DPs shows high mastery levels, with a mean of $95.83 \%(S D=$ 12.7) for our group. One child (aged 40 months) scored $2 / 6$ target responses while no other scored below 5/6 (or $83.33 \%$ ). Target responses were relatively balanced across items, with no differences between masculine and feminine items (both 95.83\%). However, two responses are worth noting. Two young children (N89 and N29, aged 3;0 and 3;4) showed no recognition of some feminine forms. We will return to this issue after we present the results on the following task, also involving colour adjectives.

\section{Colour and size adjective DPS}

We again combined results on target responses for the 32 children, as each child produced only half of all the stimuli in this task. One child (aged 3;2) refused to do the task. Her missing values were replaced by the code for no response in our analysis. We analyzed results for size and colour adjectives separately. We entered the colour data into a $2 \times 2 \times 3$ analysis of variance with gender (masculine and feminine), adjective type (variable and invariable) and items (3 adjectives) as independent variables for the colour adjectives. There was a significant effect of gender $(F(1,15) 42.72, p<.001)$ and adjective type $(F(1,15) 21.92, p<.001)$ on results. No item effects were observed. Masculine forms $(85.4 \%)$ were better produced than feminine ones (59.8\%), and invariable adjectives $(87.5 \%)$ were better produced than variable ones $(67.7 \%)$. A significant interaction of gender and adjective type was observed $(F(1,15) 26.57, p<.001)$. Invariable adjectives were produced at the same level in both feminine and masculine structures (87.5\%), while fewer correct responses were obtained on feminine $(52.1 \%)$ than masculine forms 
(83.3\%). We again verified age effects on results by entering age (eight groups) as a betweensubject factor in the analysis. Age was found to be a significant main factor affecting results $(F(7$,

8) $11.44, p=.001$ ), indicating increasing ability with age to produce appropriate adjectives within these structures. Sex did not affect performance on this task $(F(1,14) .18, \mathrm{~ns})$.

Size adjective data was entered into a $2 \times 2$ analysis of variance with gender (masculine and feminine) and size (big and small) as independent variables. An effect of gender was observed on results $(F(1,15) 4.92, p<.05)$, but not size $(F(1,15) 0.24, \mathrm{~ns})$. Masculine forms (84.1\%) were better produced than feminine ones $(81.8 \%)$. Between-subject effects for age group $(F(7,8) 15.06, p=.001)$ and $\operatorname{sex}(F(1,14) .03, \mathrm{~ns})$ were similar to those reported for the colour adjective analysis. Age effects on size and color adjective responses are presented in Figure 2. INSERT FIGURE 2 HERE

Non-target responses observed were adjective omission or no response $(10.5 \%$ of responses) and the production of gender errors on variable adjectives (e.g., la grosse maison *blanc 'the.f big.f house white.m') ( $4.5 \%$ on colour adjectives, $1.9 \%$ on size adjective, all on feminine forms). Only $1.7 \%$ of responses involved adjective commission, e.g., la petite maison grise for ... la petite maison brune 'the small grey/brown boat').

On comprehension of colour and size DPs, the mean result was $91.15 \%(S D=15.11)$. One child scored 4/12 and three scored 7, 8 and 9 out of $12(58.33-75 \%)$. The remainder scored 10 or above. Target responses were relatively balanced across items (raging from 12 to 16 target responses out of 16), with no significant differences between masculine and feminine DPs $(93.23 \%$ vs. $89.06 \%)$. The three items resulting in the lowest correct recognition across children were structures involving feminine verte and brune. As in the previous task, one child did not recognize the feminine forms of brown, while understanding the masculine form, and a second, 
slightly older child did not recognize the feminine forms of brown or green. These items are reported in Table 5 .

\section{INSERT TABLE 5 HERE}

From Table 5, we see that although child N89 can understand and produce the masculine form (no problem naming the colour) for brown and green, he cannot produce their feminine forms in the colour DP task. This is relatively common in French-speaking children of this age. However, most children can still understand the feminine forms and identify feminine objects (here, frogs) bearing these colours. This particular child does not seem to be able to produce or understand the item brune, even though he can produce and understand brun. When asked, 'Please give me the small brown house', and similarly for the big one, he told the experimenter, 'I don't have any like that.' The same interpretation applies to N29's inability to understand and comprehend verte, the feminine form of vert 'green,' as she produced and apparently understood the masculine form during colour naming. These children do not seem to be making the conceptual link between the feminine and masculine forms, as discussed here.

Because two children in our sample had shown inability to understand specific feminine adjective forms, we went back to the larger database to verify whether other children of similar age had shown difficulty recognizing or producing specific feminine adjectives. We retrieved data from an additional 18 children aged 3;0 to 3;8 (3 boys, 5 girls). One child (aged 3;6) presented difficulties producing and comprehending the feminine colour adjective brune while being able to produce and comprehend the masculine brun. Therefore, although it is quite rare,

some children show a dissociation between their comprehension and production of feminine and masculine adjectives for the same colour concept. It is not surprising that we did not find more 
children with this particular dissociation pattern between feminine and masculine forms, as the colour items were chosen precisely for their early acquisition. The fact that we found some children who did not understand them was quite surprising, however, and even counterintuitive.

\section{Spontaneous speech production}

We also analyzed spontaneous speech corpora, comprising two hundred complete utterances for each child in the study, and we verified adjective use in all DPs. We divided correct adjective production into four groups: variable feminine and masculine and invariable feminine and masculine forms. Results are presented in Table 5. A two-factor ANOVA with gender and type of adjective as within factors revealed a significant effect of adjective type $(F(1,31) 6.25, p<.05)$ in that they produced more variable than invariable adjectives, but no effect of gender $(F(1,31) 6.25, p<.05)$ and no interaction of gender and adjective type effects $(F(1,31) 6.25, p<.05)$ in production patterns.

\section{INSERT TABLE 6 HERE}

On average, the children produced 18.75 (SD 12.9) DP adjectives per sample. However the range was large, varying from 5 to 58 tokens per child. Participants under the age of 40 months, restricted their use of variable adjectives to gros 'big' and petit 'small.' Older children used many variable adjectives, including colour terms. We verified whether adjective production in the corpus was correlated with task scores. No significant correlations between task scores and types or tokens in the corpus were found. A verification of errors produced in complex DPs in the corpus reveals that only the younger participants show errors on these structures. Of the 18 children under 49 months, seven produced erroneous variable adjectives in complex DPs: two 
children on masculine forms (one error each) and six on feminine forms (between one and six errors, for a total of twelve). These erroneous productions are listed in Appendix B. Almost half of all the errors were produced by the youngest child, who made mistakes on feminine forms of 'small' and 'big' (usually with the word 'ball'). In fact, almost all the errors recorded are on 'big' and 'small,' which are high-frequency words in French. All the children who made these mistakes showed knowledge of the feminine forms of these adjectives in other contexts (except for N1 and N19 on grosse 'big.f'). We therefore propose that these are performance errors related to either lexical choice errors for the given adjectives or underspecified knowledge of the noun gender.

\section{Discussion}

The results suggest that the acquisition of size and colour adjectives and adjective concord in French seems to depend on a number of factors. Results from the elicitation tasks indicate that variable adjectives, and particularly the feminine forms, take longer to master than invariable and masculine variable forms. This is not due to the absence of the relevant concept in the child's lexicon, as the masculine forms are usually acquired, and naming of colour adjectives, as verified in the first task, is good. Furthermore, this is not necessarily due to an absence of this type of adjective in the general language corpus, as the children produced more variable than invariable adjectives in their spontaneous speech corpora. In addition, the results cannot be attributed to a lack of understanding of these forms, as our tasks generally show robust comprehension of these forms, both feminine and masculine. Finally, we cannot attribute these difficulties to the syllabic structures of feminine variable forms (involving coda consonants), as comparisons with invariable adjectives having similar structures reveal differences in the ability to produce the two types, i.e., more difficulty with variable feminine forms. 
What emerges is that children generally master masculine forms of variable adjectives first, and that feminine forms sometimes lag behind, occasionally even in terms of comprehension (as the data on three children show). Many children also show unstable ability to produce variable adjectives in their feminine forms, alternately producing the feminine and masculine forms in similar feminine contexts (e.g., $\checkmark$ la grosse maison verte but la petite maison *vert 'the big/small house green.f/green.m'). This suggests that masculine and feminine forms of variable adjectives are stored separately in the lexicon, at least initially, and that they might be competing lexical forms (thus causing output errors). Production of masculine and feminine DPs is affected in that masculine adjectives are default forms, usually of higher frequency than feminine ones, and therefore occasionally produced instead of feminine forms. Gender errors occur overwhelmingly on feminine structures. Thus, although the children in this experiment seem to have acquired the necessary syntactic abilities to produce and comprehend complex DPs (size DPs being non-problematic), they continue to have difficulty producing specific adjectives within these structures. These difficulties could stem from a number of sources. One could be an erroneous lexical choice (i.e., choosing the masculine over the feminine, or lacking a feminine form in the mental representation and using the masculine as a default). A second possibility is that these children have not yet developed a rule linking feminine and masculine forms in their lexicon. A third possibility is that they have not yet mastered gender checking and do not realize that the noun and adjective must share their phi-features. However, when reviewing the results on the adjective tasks, we observe only occasional gender errors on determiners, suggesting a solid mastery of agreement checking in the DP. A verification of the spontaneous speech corpus reveals few errors of this type. Of the 32 children in this study, 12 made concord errors on determiners. No child produced more than three types of these, or four tokens. Errors generally involved the indefinite article (un-une 'a/one'), and most involved the use of masculine rather 
than feminine forms (examples are given in 3a-b). Thirteen tokens involved commission of the masculine for feminine forms (3a), and four involved the opposite pattern (3b), while eighteen children made no errors of this type. 'the parachute it was when it rains.'

Given the generally strong abilities in determiner production and the lesser abilities in variable colour adjective production, it seems likely that retrieval of the appropriate lexical item (colour or, more rarely, size, adjective) is what is difficult for these participants. Responses for certain colours were produced at different levels of accuracy in the masculine and feminine forms, suggesting different activation levels. This interpretation is compatible with a lexicalist hypothesis for the acquisition of French adjectives. A recent account of French variable adjective representation has been proposed within a connectionist framework (St-Pierre, 2006). Although we argue here that these forms are lexicalized and not represented simply as features, as connectionist models generally propose, we do agree with St-Pierre that the children probably do not use a rule to produce these forms (at least initially), and that their acquisition and subsequent use is highly dependent on a strong representation. This also accounts for the fact that age of acquisition (or possibly frequency, as these are highly correlated, Brysbaert and Ghyselinck, 2006, Goodman et al., 2008, Juhasz, 2005) is a factor that strongly mediates the production and comprehension of these forms. The constant difference between feminine and masculine forms for variable adjectives and the inability of some children to recognize feminine forms strongly point to this interpretation. 
Finally, we should mention the difference between production abilities on size and colour adjectives. Although the size adjectives in this task are variable, error levels are quite low. Age effects are much weaker than for colour adjectives and are significant only on the fourth task. We propose that this is due to the fact that these items are extremely frequent in child speech and are therefore mastered precociously in French children. However, despite their early and common use in child language, in the context of complex DPs, errors do occur with these forms, as can be seen in the higher error levels on feminine versus masculine forms in the second and fourth task, and in the spontaneous speech errors noted in Appendix B.

Correlations between the correct production of adjectives in the corpus and the ability to perform the tasks were not significant. A study of French verbs (Royle and Elin Thordardottir, 2008) reveals correlations between regular (but not irregular) verb acquisition and the productive use of the passé composé (perfect past tense). It could be that the lack of correlations in the present study is related to the idiosyncratic nature of feminine variable adjectives in French. The reasoning is that if forms are highly idiosyncratic, it is improbable that children are integrating them into a paradigm to develop a linguistic rule. Because children are not building a paradigm, the use of a larger number of these forms in the corpus does not correlate with the emergence of the ability to produce appropriate feminine (or masculine) forms via a rule. However, this does not exclude the possibility of a rule emerging at later development stages, possibly between the fourth and sixth year (see Roulet-Amiot and Jakubowicz, 2006 for this interpretation).

It is important to note that the masculine form of adjectives (and other parts of speech with gender marking) is generally the default in French. This is not problematic in itself, but it does pose problems for rule-based approaches that consider the rule as operating from the feminine to the masculine forms (as is proposed in Paradis and El Fenne, 1995). That is, if we believe that every word representation has a "floating" consonant that is syllabified or licensed 
under certain conditions, than the word representation must contain this consonant, at least at some abstract level. However, if children learn the masculine form first, the world-final consonant may not be represented from the onset of acquisition. Thus, the child must learn masculine forms for individual adjectives, followed by (or concurrently with) feminine forms, and must then develop a lexical rule (feminine $\rightarrow$ masculine) linking the two within a schema. However, the rule has become moot, at least in the early stages of acquisition, as both feminine and masculine forms have already been learned (analagously, children might operate on the same principle for irregular past tenses of English verbs). It is possible that children go through a schemata-based process similar to that described above, and eventually develop a metalinguistic rule relating all feminine variable adjectives to their masculine counterparts via a consonant deletion rule (or its equivalent). However, this would come after the acquisition of the forms themselves, and would therefore be post hoc. Another possibility is that the rule-like nature of adjective production emerges only at later acquisition stages. Data from Roulet-Amiot and Jakubowicz (2006) indicate that this occurs around the age of 8 years, where no differences are observed between feminine and masculine adjective production. However, these results might also be caused by the stimuli used in the Roulet-Amiot and Jakubowicz data set, which seem to be varying frequency or late-acquired (no information is given on stimuli selection).

This begs the question: what is a rule? Are all possible rules actually rules? In our opinion rules should at least obey some basic learnability principle. That is, maybe true linguistic rules are those that help us acquire language, and that those learned after a given process or certain lexemes have been acquired are not truly linguistic rules, but rather, metalinguistic processes.

We could also conceive of linguistic rules as being situated on a continuum from best to worst, not necessarily in terms of Occam's Razor, but in terms of early versus late acquisition (within a given domain: e.g., phonology, syntax, semantics). Better rules would be acquired early 
and lesser rules would take longer to acquire. Which rules could be acquired easily? A number of researchers have shown that linguistic and psycholinguistic factors can help or hinder the processing of words. We would expect these same factors to affect acquisition patterns. Thus, regular rules that have predictable morphological patterns would be acquired more robustly than subregular and irregular forms (Marcus et al., 1992; Pinker, 1999; Royle, 2007). Pattern frequency (regular versus subregular) should also be a factor mediating acquisition (Marcus, et al. 1995; Say and Clahsen, 2002; Royle, 2007). Semantic regularity within the rule has been shown to be a factor in the acquisition of derived forms in Dutch and Finnish (Bertram et al., 2000a; 2000b). Thus a number of factors could affect how children process words, regularity being one. While a number of rules could be acquired early due to their highly regular phonology, morphology, syntax or semantics, rules that are highly idiosyncratic would be at the other extreme of the continuum from best to worst. They would be based on some common property (in French adjectives, consonant deletion, and in English irregular verbs, vowel ablaut) in order to qualify, but they would probably not be acquired in early acquisition stages. In fact, they might never achieve the coveted status of a rule, and could remain fragile and subject to overregularization or even death.

\section{Conclusion}

We have shown that early-stage acquisition of French variable adjectives is not a productive rule-driven process. Although feature-checking and DP structure seem to be in place (i.e., the ability to produce appropriate determiners and size-adjective DPs), and although children as young as 3 years old know the concepts of and lexical items for colour adjectives, they still produce erroneous structures in feminine colour DPs in the oldest age group studied (4;11 years). Even though some of the non-target productions were not necessarily 
ungrammatical, they occurred more often 1) within feminine DPs and 2) with variable adjectives. We surmised that the source of difficulty for feminine DPs is retrieving a feminine adjective, which is lexicalized and therefore in competition with the masculine adjective denoting the same concept. This additional processing load (lexical competition) would therefore create a situation where target production is reduced in circumstances demanding more processing (i.e., complex feminine DPs). However, we cannot support the entirety of our claims with the behavioural data presented here. For example, although children do seem to have a feature checking process, in that they almost never produce feminine instead of masculine adjectives in masculine contexts, and they have a rather robust ability to produce appropriate determiners, we do not actually know whether or not children have developed this grammatical ability. We must search for new ways to approach this question. One solution would be to use neuroimaging techniques that are sensitive to subtle linguistic processes, such as agreement. A number of studies tried this method using event-related potential technology with adults (Dutch: Hagoort and Brown, 1999; Spanish: Barber and Carreiras, 2005; Demestre et al., 1999; Wicha et al., 2003; and Italian: Balconi and Pazzoli, 2005). This promises to be a fruitful approach to verify adjective and gender processing in Frenchspeaking children.

\section{[8 764 words]}




\section{References}

Aronoff, M. (1976). Word formation in Generative Grammar. Cambridge, MA: MIT Press.

Balconi, M. and Pozzoli, U. (2005). Comprehending semantic and grammatical violations in Italian. N400 and P600 comparison with visual and auditory stimuli. Journal of Psycholinguistic Research, 34.1: 71-98.

Barber, H. and Carreiras, M. (2003). Integrating gender and number information in Spanish word pairs: An ERP study. Cortex, 39.1: 465-482.

Bassano, D. and Maillochon I. (1994). Early grammatical and prosodic marking of utterance modality in French: A longitudinal case study. Journal of Child Language, 21: 649-675.

Bedore, L. M. and Leonard, L. B. (2001). Grammatical Morphology Deficits in Spanish-speaking Children with Specific Language Impairment. Journal of Speech, Language, and Hearing Research, 44.1: 905-924.

Bertram, R., Schreuder, R. and Baayen, R. H. (2000). The balance of storage and computation in morphological processing: The role of word formation type, affixal homonymy and productivity. Journal of Experimental Psychology: Learning, Memory, and Cognition, 26.2: $1-23$.

Bertram, R., Laine, M. and Virkkala, M. M. (2000). The role of derivational morphology in vocabulary acquisition. Get by with a little help from my morpheme friends. Scandinavian Journal of Psychology, 41: 287-296.

Brysbaert, M. and Ghyselinck, M. (2006). The effect of age of acquisition: Partly frequency related, partly frequency independent. Visual Cognition, 13.7-8: 992-1011.

Burani, C. and Caramazza, A. (1987). Representation and processing of derived words. Language and Cognitive Processes, 2: 217-227. 
ACQUisition of QUEBEC FRENCH ADJECTIVES AS REVEALED BY ELICITATION DATA

Bybee, J. L. and Slobin, D. I. (1982). Rules and schemas in the development and use of the English past tense. Language, 58.2: 265-289.

Clahsen, H. and Rothweiler, M. (1992). Inflectional rules in children's grammars: Evidence from German Participles. Yearbook of Morphology, 1.34: 255-288.

Comrie, B. (1999). Grammatical gender Ssystems: A linguist's assessment. Journal of Psycholinguistic Research, 28.5: 457-466.

De Cat, C. and Plunkett, B. (2002) QU' est ce qu' i(1) dit, celui+Là ? Notes méthodologiques sur la transcription d'un corpus francophone. In: C. D. Pusch and W. Raible (eds), Romanistische Korpuslinguistik: Korpora und gesprochene Sprache / Romance Corpus Linguistics: Corpora and Spoken Language. Tübingen: Narr.

Demestre, J., Meltzer, S., García-Albea, J. E. and Vigil, A. (1999). Identifying the null subject: Evidence from event-related brain potentials. Journal of Psycholinguistic Research, 28: 293312.

Desrochers, A., Paivio, A. and Desrochers, S. (1989). L'effet de la fréquence d'usage des noms inanimés et de la valeur prédictive de leur terminaison sur l'identification du genre grammatical. Canadian Journal of Psychology Revue Canadienne de Psychologie, 43.1: $62-73$.

Dunn, L., Thériault-Whalen, C. and Dunn, L.M. (1993). Échelle de vocabulaire en images Peabody. Toronto: Psycan.

Elin Thordardottir (2005). Early lexical and syntactic development in Quebec French and English: Implications for cross-linguistic and bilingual assessment. International Journal of Language and Communication Disorders, 40.3: 243-278.

Fink, R. (1985). French adjective morphophonemic patterns: Their Generalization and Representation. Linguistics, 23: 567-596. 
ACQUisition of QUEBEC FRENCH ADJECTIVES AS REVEALED BY ELICITATION DATA

Goodman, J. C., Dale, P. S. and Li, P. (2008). Does frequency count? Parental input and the acquisition of vocabulary. Journal of Child Language, 35.3: 515-531.

Hagoort, P. and Brown, C. M. (1999). Gender electrified: ERP evidence on the syntactic nature of gender processing. Journal of Psycholinguistic Research,28.6: 715-728.

Juhasz, B. J. (2005). Age-of-acquisition effects in word and picture identification. Psychological Bulletin, 131.5: 684-712.

Kim, J. J., Marcus, G. F., Pinker, S., Hollander, M. and Coppola, M. (1994). Sensitivity of children's inflection to grammatical structure. Journal of Child Language, 21.1: 173-209.

Leonard, L., Salameh, E.-K. and Hansson, K. (2001). Noun Phrase morphology in SwedishSpeaking children with Specific Language Impairment. Applied Psycholinguistics, 22: 619-639.

Marchman, V. A. and Bates, E. (1991). Vocabulary size and composition as predictors of morphological development. Papers and Reports on Child Language Development, 30: 64-71.

Marchman, V. A. and Bates, E. (1994). Continuity in lexical and morphological development: A test of the Critical Mass Hypothesis. Journal of Child Language, 21.2: 339-366.

Marcus, G. F. (2001) The algebraic mind: Integrating connectionism and cognitive science. Cambridge, MA: MIT Press.

Marcus, G. F., Brinkmann, U., Clahsen, H., Wiese, R. and Pinker, S. (1995). German inflection: the exception that proves the rule. Cognitive Psychology, 29: 189-256.

Marcus, G. F., Pinker, S., Ullman, M., Hollander, M., Rosen, T. J. and Xu, F. (1992). Overregularization in language acquisition. Monographs of the Society for Research in Child Development, 57.4, (serial No. 228). 
ACQUisition of QUEBEC FRENCH ADJECTIVES AS REVEALED BY ELICITATION DATA

Matsuo, A. and Eisenbeiss, S. (2003). Acquisition of case in German and Japanese. Paper presented at the 3-place Predicate Workshop, Max Planck Institute, Nijmegen, The Netherlands, 14-16 May.

Miller, J. and Chapman, R. (1984-2002). Systemic analysis of language transcripts: Software for analyzing English and Spanish language samples. Madison, WI: Language Analysis Laboratory, University of Wisconsin-Madison.

Nelson, D. (2005). French gender assignment Revisited. Word, 56.1: 19-38.

New, B., Pallier, C., Brysbaert, M. and Ferrand, L. (2004). Lexique 2: A new French lexical database. Behaviour Research Methods, Instruments, and Computers, 36.3: 516-524.

Paradis, C. and El Fenne, F. (1995). French verbal inflection revisited: constraints, repairs and floating consonants. Lingua, 19: 169-204.

Picard, M. (1996). The Empty Onset Principle: A problematic phonological constraint. Revue québecoise de linguistique théorique et appliquée,13.1-4: 195-201.

Pinker, S. (1999). Words and rules. New York: Basic Books.

Pinker, S. and Prince, A. (1994). Regular and irregular morphology and the psychological status of rules of grammar. In S. D. Lima, R. L Corrigan, and G. K. Iverson (eds), The reality of linguistic rules. Amsterdam: John Benjamins, pp. 321-351.

Pirvulescu, M. and Belzil, I. (2008). The acquisition of past participle agreement in Québec French L1. Language Acquisition, 15.2: 75-88.

Roid, G. and Miller, L. (1996). The Leiter International Performance Scale-Revised. Dale, IL: Wood Stoelting Co.

Roulet-Amiot, L. and Jakubovicz, C. (2006). Production and perception of gender agreement in French SLI. Advances in Speech-Language Pathology, 8.4: 335-346. 
ACQUisition of QUEBEC FRENCH ADJECTIVES AS REVEALED BY ELICITATION DATA

Royle, P. (2007). Variable effects of morphology and frequency on inflection patterns of French preschoolers. The Mental Lexicon Journal, 2.1: 103-125.

Royle, P. (2005-2008). Outils morphosyntaxiques pour le dépistage de la dysphasie chez les jeunes francophones, FQRSC 2006-NP-104790.

Royle, P. , Vial, M. and Valois, D. (2005, accepted). The acquisition of concord in French and Spanish Determiner Phrases, two elicitation experiments. Revista de la Asociación Española de Lingüistica Aplicada.

Royle, P. and Elin Thordardottir (2008). Elicitation of the perfect past in French pre-schoolers with and without SLI. Applied Psycholinguistics, 29.3: 241-265.

Say, T. and Clahsen, H. (2002). Words, rules and stems in the Italian mental lexicon. In S. Nooteboom, F. Weerman and F.Wijnen, F. (eds), Storage and computation in the language faculty. Dordrecht: Kluwer, pp. 93-129.

St-Pierre, M.-C. (2006). Traitement auditif, traitement phonologique et acquisition de la morphologie dans la dyslexie développementale. Unpublished Ph.D. dissertation, Université de Montréal.

Stockall, L. and Marantz, A. (2006). A single route, full decomposition model of morphological complexity: MEG evidence. The Mental Lexicon,1.1: 85-193.

Tomasello, M. (2002). The emergence of grammar in early child language In T. Givon and B. F. Malle (eds), The evolution of language out of pre-langauge. Amsterdam: John Benjamins, pp. 309-328.

Tranel, B. (2000). Aspects de la phonologie du Français et la théorie de l'optimalité. Langue française, 126: 39-772.

Trudeau, N., Poulin-Dubois, D., Frank, I., Courcy, A. and Sutton, A. (2008). Normalisation et validation de la version québécoise des MacArthur Communicative Development 
Inventories (MCDI): Université de Montréal.

http://132.204.140.194/fmi/xsl/trudeau_N_outil_eval/addrecord.xsl?-view

Valois, D., Royle, P., Bourdua-Roy, E. and Sutton, A. (to appear). Étude transversale de l'ellipse du nom en français et le rôle des données de l'acquisition pour la théorie linguistique. Revue canadienne de linguistique/Canadian Journal of Linguistics.

Valois, D. and Royle, P. (2009). Partitivity, atomization, and Noun-Drop: A longitudinal study of French child language. Language Acquisition, 16.2: 82-105.

Wicha, N. Y. Y., Moreno, E. M. and Kutas, M. (2003). Expecting gender: An event related brain potential study on the role of grammatical gender in comprehending a line drawing within a written sentence in Spanish. Cortex, 39.3: 483-508.

\section{Acknowledgments:}

The first author acknowledges the support of the FQRSC (2006-NP-104790). We thank Margaret McKyes for her editing, numerous research assistants, and particularly N. Bourguignon, I. Delorme, L. Gazhlé, A. Michaud and J. Toupin for data transcription and analysis. Finally, this study would not have been possible without the participation of the children and their families. 
Appendix A - Colour adjective frequencies in the Frantext Database (New et al., 2001)

\begin{tabular}{|c|c|c|c|c|}
\hline & Lemma & $\begin{array}{c}\text { Phonological } \\
\text { form }\end{array}$ & Cumfreq $^{a}$ & Webcumfreq ${ }^{\mathrm{b}}$ \\
\hline \multirow[t]{3}{*}{ Variable adjectives } & $\begin{array}{l}\text { blanc } \\
\text { 'white' }\end{array}$ & blã / blã & 341.43 & 56.26 \\
\hline & $\begin{array}{l}\text { brun } \\
\text { 'brown' }\end{array}$ & brõ / bryn & 52.74 & 67.95 \\
\hline & $\begin{array}{l}\text { vert } \\
\text { 'green' }\end{array}$ & vєь / vعьt & 127.19 & 30.64 \\
\hline Mean (SD) & & & $173.79(149.88)$ & $31.23(24.74)$ \\
\hline \multirow[t]{3}{*}{ Invariable adjectives } & $\begin{array}{l}\text { jaune } \\
\text { 'yellow' }\end{array}$ & zon & 85.87 & 20.68 \\
\hline & $\begin{array}{l}\text { rouge } \\
\text { 'red' }\end{array}$ & ruz & 219.03 & 31.38 \\
\hline & $\begin{array}{l}\text { noir } \\
\text { 'black' }\end{array}$ & nwaь & 364.7 & 41.20 \\
\hline Mean (SD) & & & $223.29(139.6)$ & $31.09(10.27)$ \\
\hline \multirow[t]{2}{*}{ Practice items } & $\begin{array}{l}\text { bleu } \\
\text { 'blue' }\end{array}$ & blø & 170.49 & 25.48 \\
\hline & $\begin{array}{l}\text { rose } \\
\text { 'pink' }\end{array}$ & $\mathrm{roz}$ & 106.29 & 14.7 \\
\hline
\end{tabular}

${ }^{\mathrm{a}}$ Sum of orthographic (surface) frequencies in text corpus 
ACQUiSITION OF QUEBEC FRENCH ADJECTIVES AS REVEALED BY ELICITATION DATA

${ }^{\mathrm{b}}$ French web frequency, $/ 1,000$ 
Appendix B - Erroneous variable adjectives in complex DPs from spontaneous speech samples N2 (36): $\quad$ *un *gros boule

a.m big.m ball 'a big ball'

*un *gros maman

a.m big.m mommy 'a big mommy'

ah *gros boule

ah big.m ball 'ah, big ball'

*un *gros boule

a.m big.m ball 'a big ball'

*un *petit boule

a.m small.m ball 'a small ball'

une *petit boule

a.f small.m ball 'a small ball'

N19 (39): * *un *gros saucisse

a.m big.m saussage 'a big saussage'

N1 (40): $\quad$ *la *petite XX crocodile

the.f small.f XX crocodile 'the small crocodile'

les *gros portes

the.pl big.mpl doors 'the big doors'

N13 (44): * *une *petite __ \{train\}

a.f small.f__ 'a small one'

N36 (44): $\quad$ *une *grosse accident

a.f big.f accident $\quad$ 'a big accident' 
(This is not a case of dialectical variation, as the child previously used the masculine of accident.)

N74 (47): $\quad$ *tout la pâteàmodeler

all.m the.f play dough 'all of the play dough'

N21 (49): $\quad$ *un *petit affaire comme ça

a.m small.m thing like this/that 'a little thing like this/that'

*mon *petit affaire

my.m little.m thing 'my little thing' 


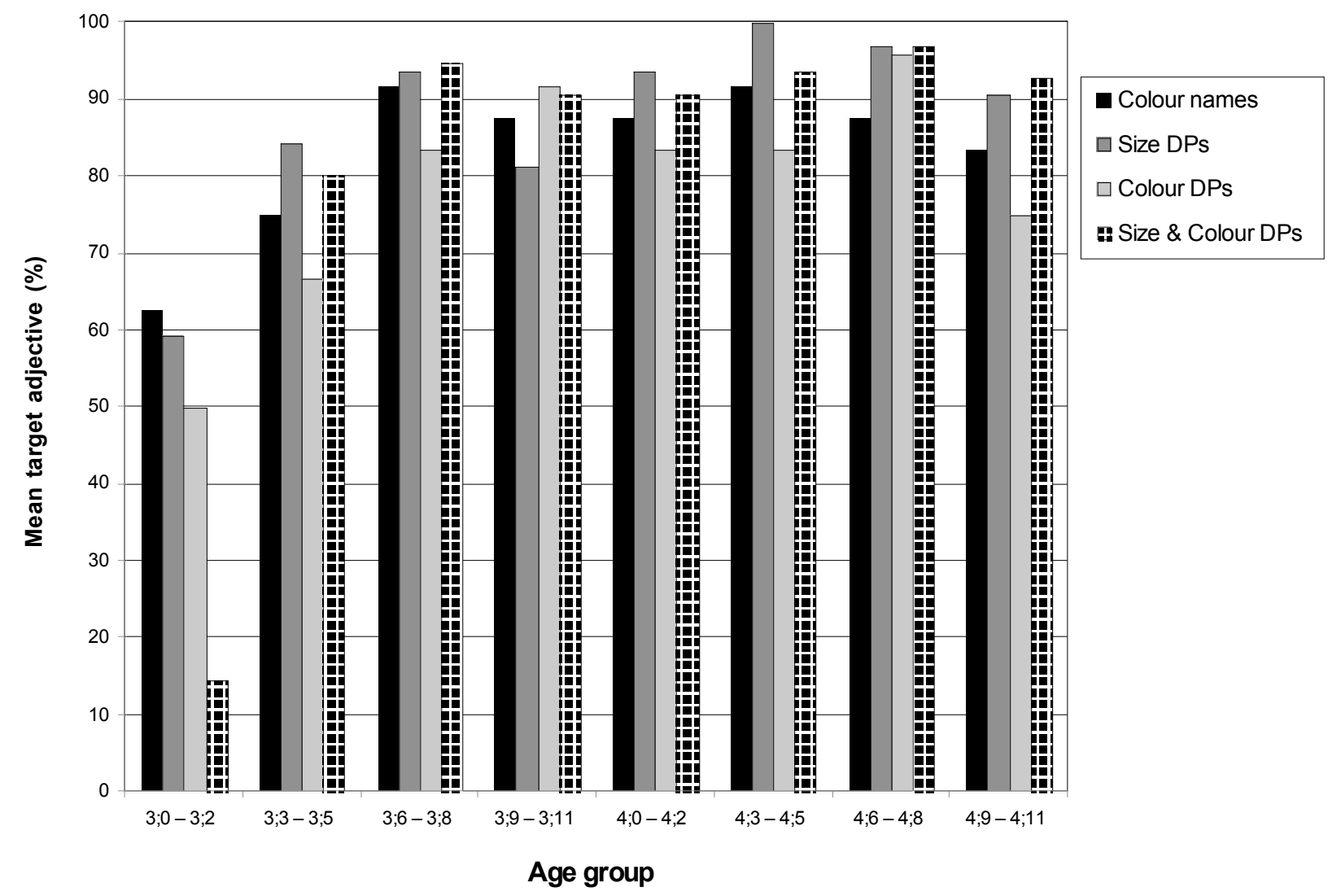

Figure 1: Response accuracy for the eight age groups on the four tasks. 


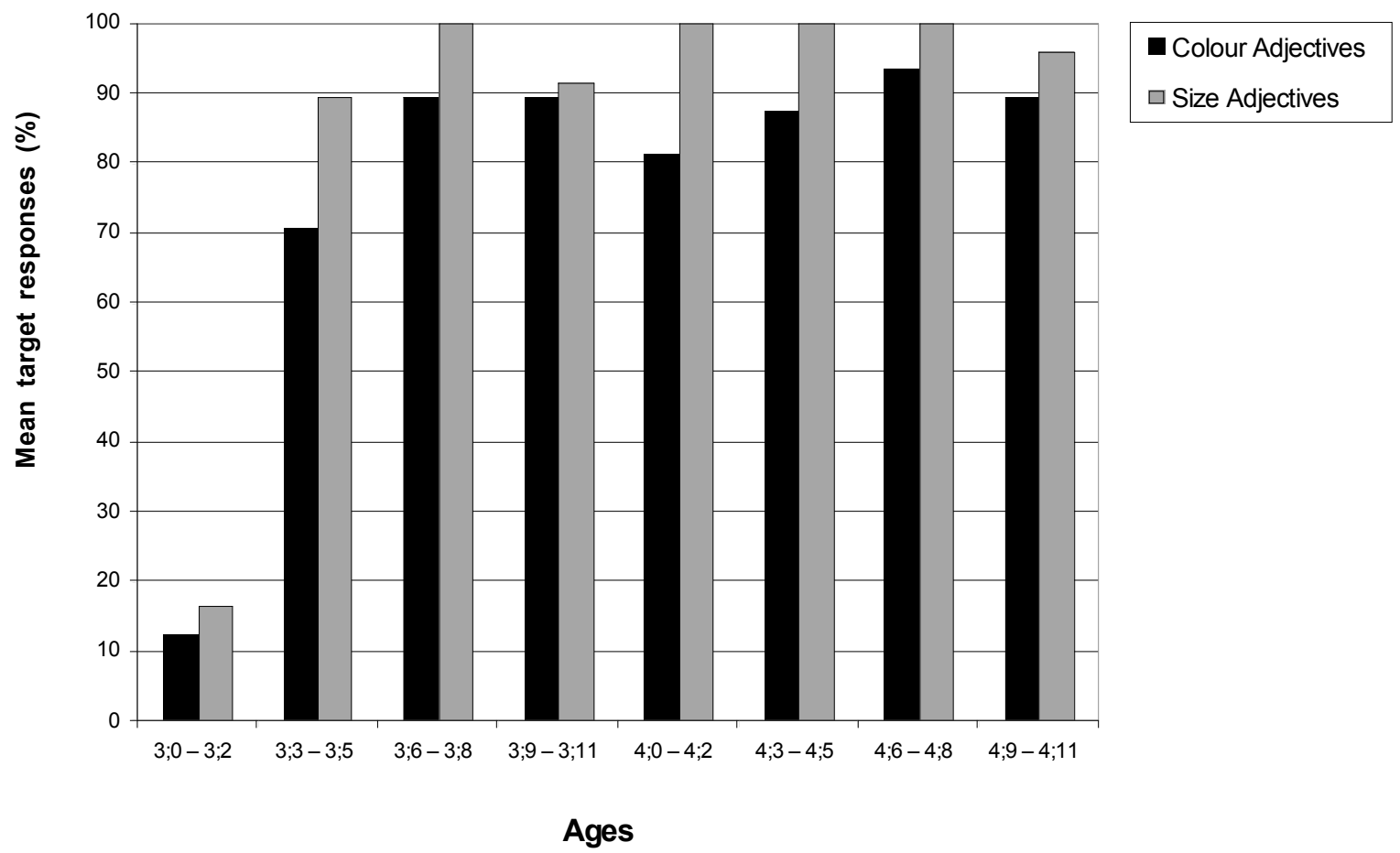

Figure 2: Age effects on target adjective production in the size and color DP task. 
ACQUisition OF QUEBEC FRENCH ADJECTIVES AS REVEALED BY ELICITATION DATA

Table 1: Examples of variable adjectives in French

\begin{tabular}{|c|c|c|}
\hline Masculine & Feminine & Gloss \\
\hline Brun [вьюе̃] & Brune [bьуn] & Brown \\
\hline $\operatorname{Vert}[\mathrm{v \varepsilon} \mathrm{s}]$ & Verte [veьt] & Green \\
\hline Grand [gьа̃] & Grande [gьãd] & Big/tall \\
\hline Petit [pœtsi] & Petite [pœtsit] & Small \\
\hline Gros [gьо] & Grosse [gкоs] & $\mathrm{Big} / \mathrm{fat}$ \\
\hline Ouvert [uveь] & Ouverte [uvest] & Open \\
\hline Géant [geã] & Géante [geãt] & Giant \\
\hline $\operatorname{Doux}[\mathrm{du}]$ & Douce [dus] & Gentle/soft \\
\hline
\end{tabular}


Table 2: First observations of variable adjective production in the Sutton and Pauline corpora and number of different children (out of a possible 14) using them in the Sutton corpus

\begin{tabular}{|c|c|c|c|c|}
\hline \multirow[b]{4}{*}{ Adjective } & \multicolumn{2}{|c|}{ Sutton corpus } & \multicolumn{2}{|c|}{ Pauline corpus } \\
\hline & \multicolumn{2}{|c|}{ (age of first occurrence and } & \multicolumn{2}{|c|}{ (age of first occurrence) } \\
\hline & numbe & ldren) & & \\
\hline & Masculine & Feminine & Masculine & Feminine \\
\hline Petit/e 'small' & $1: 11(8)$ & $2: 3(4)$ & $1: 10: 07$ & $2 ; 3: 20$ \\
\hline Gros/se 'big/fat' & $2: 0(2)$ & $2: 5(3)$ & $2 ; 5: 20$ & $2 ; 6: 13$ \\
\hline Beau/belle 'beautiful' & & & $2 ; 1: 17$ & \\
\hline Grand/e 'big/tall' & & $2: 7(1)$ & $2 ; 2: 29$ & $2 ; 5: 20$ \\
\hline Vert/e 'green' & $3 ; 0(1)$ & $2: 4(5)$ & & \\
\hline Blanc/he 'white' & & & & $2 ; 5: 07$ \\
\hline Chaud/e 'hot' & & & & $2 ; 5: 20$ \\
\hline Froid/e 'cold' & & & & $2 ; 5: 20$ \\
\hline Tous/toutes 'all' & & & & $2 ; 6: 13$ \\
\hline Bon/ne 'good' & & $2: 11(1)$ & & \\
\hline
\end{tabular}


Table 3: Participant characteristics $(N=32)$ by age group

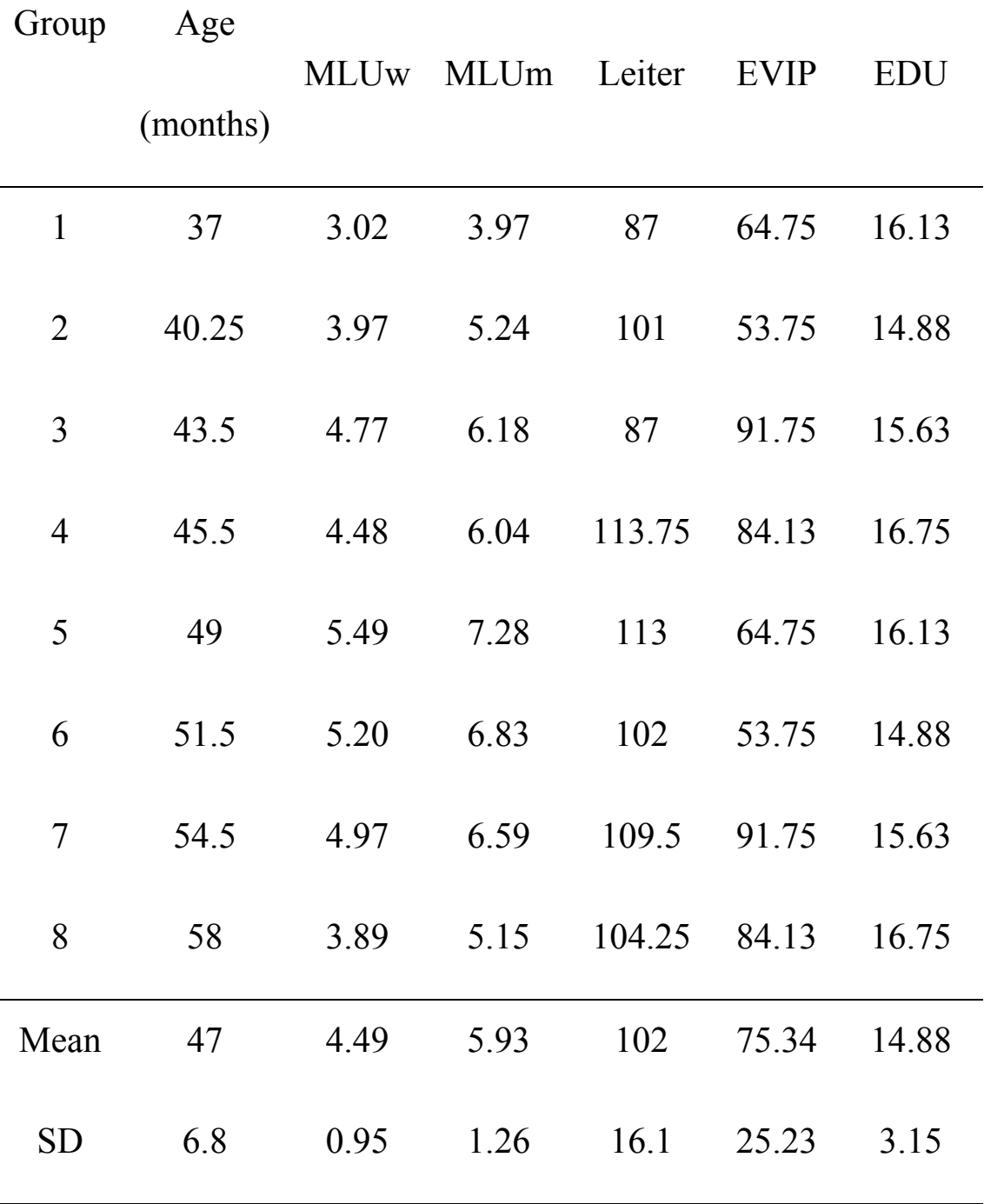

MLUw $=$ mean length of utterance in words

MLUm $=$ MLU in morphemes

Leiter $=$ memory screen subtests, IQ

EVIP $=$ receptive vocabulary score, percentile rank

$\mathrm{EDU}=$ mean parental education in years 
ACQUiSITION OF QUEBEC FRENCH ADJECTIVES AS REVEALED BY ELICITATION DATA

Table 4: Mean target production (tokens and percentages) of colour adjectives in DPs by French-speaking children $(n=16)$

\begin{tabular}{lccc}
\hline & Masculine & Feminine & Mean \\
\cline { 2 - 4 } Variable & $38 / 4879.2$ & $20 / 4842.8$ & $56 / 9660.6$ \\
Invariable & $46 / 4895.8$ & $47 / 4897.9$ & $77 / 9696.9$ \\
Mean & $78 / 9687.5$ & $55 / 9670.0$ & \\
\hline
\end{tabular}


ACQUisition of QUEBEC FRENCH ADJECTIVES AS REVEALED BY ELICITATION DATA

Table 5: Problematic colour items for two children

\begin{tabular}{|c|c|c|c|c|}
\hline \multirow[b]{2}{*}{ Child } & \multicolumn{2}{|c|}{ Colour Naming (masculine) } & \multicolumn{2}{|c|}{ Colour DP Production } \\
\hline & Production & Comprehension & Production & Comprehension \\
\hline \multirow{2}{*}{ N89 $(3 ; 0)$} & & & verte & \\
\hline & & & brune & brune \\
\hline \multirow{2}{*}{ N29 $(3 ; 4)$} & brun & brun & & verte \\
\hline & & & brune & brune \\
\hline
\end{tabular}


ACQUiSITION OF QUEBEC FRENCH ADJECTIVES AS REVEALED BY ELICITATION DATA

Table 6. Target adjective production in DPs in the spontaneous speech corpora

Variable Invariable

$\begin{array}{lcccc}\text { Context } & \text { Feminine } & \text { Masculine } & \text { Feminine } & \text { Masculine } \\ \text { Tokens } & 151 & 202 & 114 & 133\end{array}$

